\title{
Synthesis, Characterization and Antimicrobial Activities of Copper, Nickel, Cobalt, Chromium Complexes Derived from (Z)-4-Fluoro- $N$-(2,7-dimethylhept-6-enylidene) benzenamine
}

\author{
Sridhar.G, ${ }^{a}$ Mohammed Bilal.I, ${ }^{*, a}$ Easwaramoorthy.D, ${ }^{a}$ Kutti Rani.S, ${ }^{a}$ Siva Kumar.B ${ }^{b}$ \\ and Chelli Sai Manohar ${ }^{b}$
}

${ }^{a}$ Department of Chemistry, B. S. Abdur Rahman University, 600048 Chennai, India

${ }^{b}$ Sri Sathya Sai Institute of Higher Learning, 515134 Prasanthi Nilayam, India

\begin{abstract}
Melonal is a relatively unexplored ingredient in the field of chemistry with excellent sensory properties. The synthesis and characterization of novel transition $3 \mathrm{~d}$ metal complexes of copper(II), nickel(II), cobalt(II) and chromium(III) involving the Schiff base of melonal were explored to examine their biological activity. Characterization of the complexes was carried out using matrix-assisted laser desorption/ionization-time-of-flight (MALDI-TOF), gas chromatography-mass spectrometry (GC-MS), thermogravimetric analysis (TGA), UV-Visible and infrared (IR) spectrophotometry. The antimicrobial studies were conducted against six bacterial strains and six fungi. The minimum inhibition concentration observed was compared against the standard antibiotic gentamycin and the anti-fungal drug amphotericin. The activity studies indicated that cobalt(II) complex exhibited activity better than standard drug amphotericin against Penicillium chrysogenum. Molecular docking study confirms the protein binding and supports the experimental finding. Binuclear cobalt(II) and chromium(III) bridging complexes of Schiff base ligand were obtained.
\end{abstract}

Keywords: azomethine, chromium(III) complex, melonal, bridging complex, docking, DFT

\section{Introduction}

Melonal (2,6-dimethyl-5-heptenaldehyde) is less explored in the field of chemistry and an interesting aldehyde used in sensory science. Melonal is credited with excellent sensory properties. It is widely used in flavor and fragrance industries for its fruity melon taste and odor. We have prepared Schiff base involving this melon aldehyde and 4-fluoro aniline. Over the years, antibiotic compounds have been used to manage infections resulting from various environments. ${ }^{1}$ These powerful agents interfere with the growth and reproduction of organisms like bacteria, fungi, parasites, virus, etc. Besides providing resistance against some fungal and bacterial strains, a limited number of compounds are available for the treatment of fungal and bacterial infections.

In general, Schiff bases have been used in the preparation of many drugs and they possess a broad spectrum of

*e-mail: bilalismail@bsauniv.ac.in biological activities such as antifungal, ${ }^{2}$ antibacterial, ${ }^{3}$ antiinflammatory and anticancer activities. ${ }^{4-7}$ In this context, with the aim of developing new antifungal and antibacterial compounds, we report the synthesis, characterization of a novel Schiff base and its metal complexes and their antifungal, antibacterial properties. While the antibacterial studies exhibit moderate activity against the species studied, antifungal studies revealed an interesting result. The antifungal activity studies indicated that cobalt(II) complex exhibited activity better than standard drug amphotericin against Pencillium chrysogenum.

The present work is the study of copper(II), nickel(II), cobalt(II), chromium(III) metal complexes of the Schiff base derived from 2,6-dimethyl-5-heptenaldehyde and 4-fluoro aniline. The work is supported by density functional theory (DFT) and molecular docking studies. The binding affinity is confirmed by docking Schiff base ligand with PAF protein. The activity predictions were conducted using Hex scores for ligand and its metal complexes. The theoretical studies undertaken strengthen the experimental results. 


\section{Experimental}

Materials

Melonal purchased from Sigma-Aldrich was used for the preparation of Schiff base. All the other chemicals used were of analytical reagent grade (AR). In order to derive the empirical formulae of the metal complexes, Bruker Ultra flextreme model of matrix-assisted laser desorption/ionization-time-of-flight (MALDI-TOF) Agilent 6890N GC fitted with 5973MSD was used. ${ }^{1} \mathrm{H}$ nuclear magnetic resonance (NMR) was recorded on Bruker Advance III. Fourier transform infrared (FTIR) spectra were recorded with Thermo Nicolet, Avatar 370. Absorption spectra were recorded using Varian, Cary 5000 UV-Visible spectrophotometer. For studying the thermal decomposition, thermogravimetric analysis (TGA) was carried out on a PerkinElmer, Diamond TGA apparatus. Molar conductivity measurements were recorded on Systronic conductivity meter type 304 .

\section{Synthesis of Schiff base ligand}

The Schiff base ligand (L) was prepared by the condensation of 2,6-dimethyl-5-heptenaldehyde and 4-fluoro aniline in 1:1 molar ratio by refluxing in 2-propanol for $3 \mathrm{~h}$. The solid product formed under equilibration at room temperature (RT) was separated by filtration, purified by crystallization with ethanol and washed with acetone. This was then dried in a vacuum over anhydrous calcium chloride until a beige colored crystalline product of Schiff base was obtained and recrystallized (yield 84\%). The ligand [(Z)-4-fluoro- $N$-(2,6-dimethylhept-5-enylidene) benzenamine] was characterized by gas chromatography mass spectrometry (GC-MS), ${ }^{1} \mathrm{H}$ NMR, UV-Vis, FTIR spectroscopy and TGA (Scheme 1).

\section{Synthesis of metal complexes}

Copper, nickel, cobalt and chromium complexes with the Schiff base were prepared as described by Nejati and Rezvani. ${ }^{8}$ An equimolar $20 \mathrm{~mL}$ ethanolic solution of metal salts $\left[\mathrm{Cu}\left(\mathrm{NO}_{3}\right)_{2} \cdot 3 \mathrm{H}_{2} \mathrm{O} / \mathrm{Ni}\left(\mathrm{NO}_{3}\right)_{2} \cdot 6 \mathrm{H}_{2} \mathrm{O} / \mathrm{CoCl}_{2} \cdot 6 \mathrm{H}_{2} \mathrm{O} /\right.$ $\left.\mathrm{CrCl}_{3} \cdot 6 \mathrm{H}_{2} \mathrm{O}\right]$ were added to the solution of ligand and refluxed for $4 \mathrm{~h}$. The copper complex was obtained as brown crystals (yield 84\%) and the nickel complex was obtained as green crystals (yield 81\%). The cobalt complex was reddish brown (yield 86\%) and the chromium complex was brown (yield $82 \%$ ). The microcrystals were collected by filtration, washed with absolute ethanol, recrystallized from ethanol/ chloroform (1:3, v/v) and dried in a vacuum desiccator over calcium chloride. The metal complexes were characterized by MALDI-TOF, TGA, IR and UV-Vis spectra.

\section{Results and Discussion}

\section{Characterization of Schiff base}

Mass spectra clearly indicated the molecular weight of the compound and the resulting fragmentation pattern provided information for elucidating the structure of the molecule (Figure 1).

The electron impact mass spectra of Schiff base ligand was recorded and investigated at $70 \mathrm{eV}$ of electron energy which showed a well-defined parent peak at $\mathrm{m} / \mathrm{z} 233$ (calcd. 233.3). This could be attributed to $\mathrm{C}_{15} \mathrm{H}_{20} \mathrm{NF}$.

The absence of any frequency in $1700 \mathrm{~cm}^{-1}$ in IR spectra indicated the completion of the reaction between aldehyde and amine. The appearance of a stretching vibration $v_{(\mathrm{C}=\mathrm{N})}$ at $1582 \mathrm{~cm}^{-1}$ confirming the Schiff base formation (Figure 2).

NMR spectrum of the Schiff base ligand confirms the presence of 20 protons which is line with the proposed molecular formula $\left(\mathrm{C}_{15} \mathrm{H}_{20} \mathrm{NF}\right)$. ${ }^{1} \mathrm{H} \mathrm{NMR}(399.65 \mathrm{MHz}$, $\left.\mathrm{CDCl}_{3}\right) \delta 1.38(\mathrm{~s}, 3 \mathrm{H}), 1.19(\mathrm{~s}, 3 \mathrm{H}), 2.98(\mathrm{t}, 1 \mathrm{H}), 2.19(\mathrm{~m}$, 1H), $2.41(\mathrm{~m}, 1 \mathrm{H}), 1.59(\mathrm{~m}, 1 \mathrm{H}), 1.90(\mathrm{~m}, 1 \mathrm{H}), 2.85(\mathrm{~m}$, $1 \mathrm{H}), 1.41(\mathrm{~d}, 3 \mathrm{H}), 7.85(\mathrm{~d}, J 8.4 \mathrm{~Hz}, 2 \mathrm{H}), 7.24(\mathrm{dd}, J$ 8.8, $2.4 \mathrm{~Hz}, 2 \mathrm{H}), 7.43$ (d, 1H, J $2 \mathrm{~Hz}$ ) (Figure 3). ${ }^{9}$

\section{Characterization of Schiff base-metal complex}

MALDI-TOF was performed with $\alpha$-cyano4-hydroxycinnamic acid (4-HCCA) matrix under a $2 \mathrm{kHz}$ laser and energy of $30 \mathrm{~kJ}$. All the complexes showed a peak starting above 500 amu., indicating that the transition metal complexes synthesized consist of more than one Schiff base ligand. The MALDI-TOF chromatogram of copper(II) complex showed a molecular ion peak $m / z 610.4$ (calcd. 610.2) of $\left[\mathrm{Cu}(\mathrm{L})_{2}\left(\mathrm{NO}_{3}\right) \mathrm{H}_{2} \mathrm{O}\right]$.

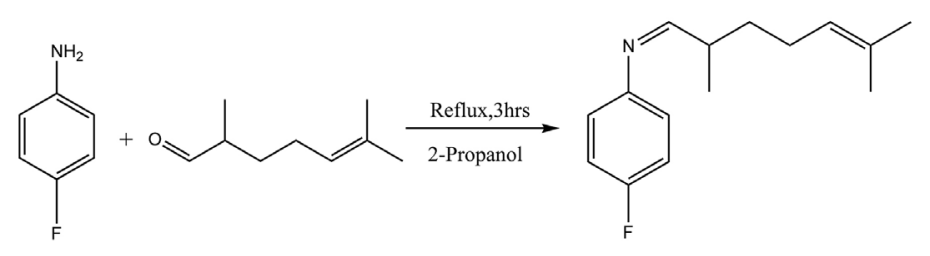

Scheme 1. Synthesis of Schiff base ligand. 


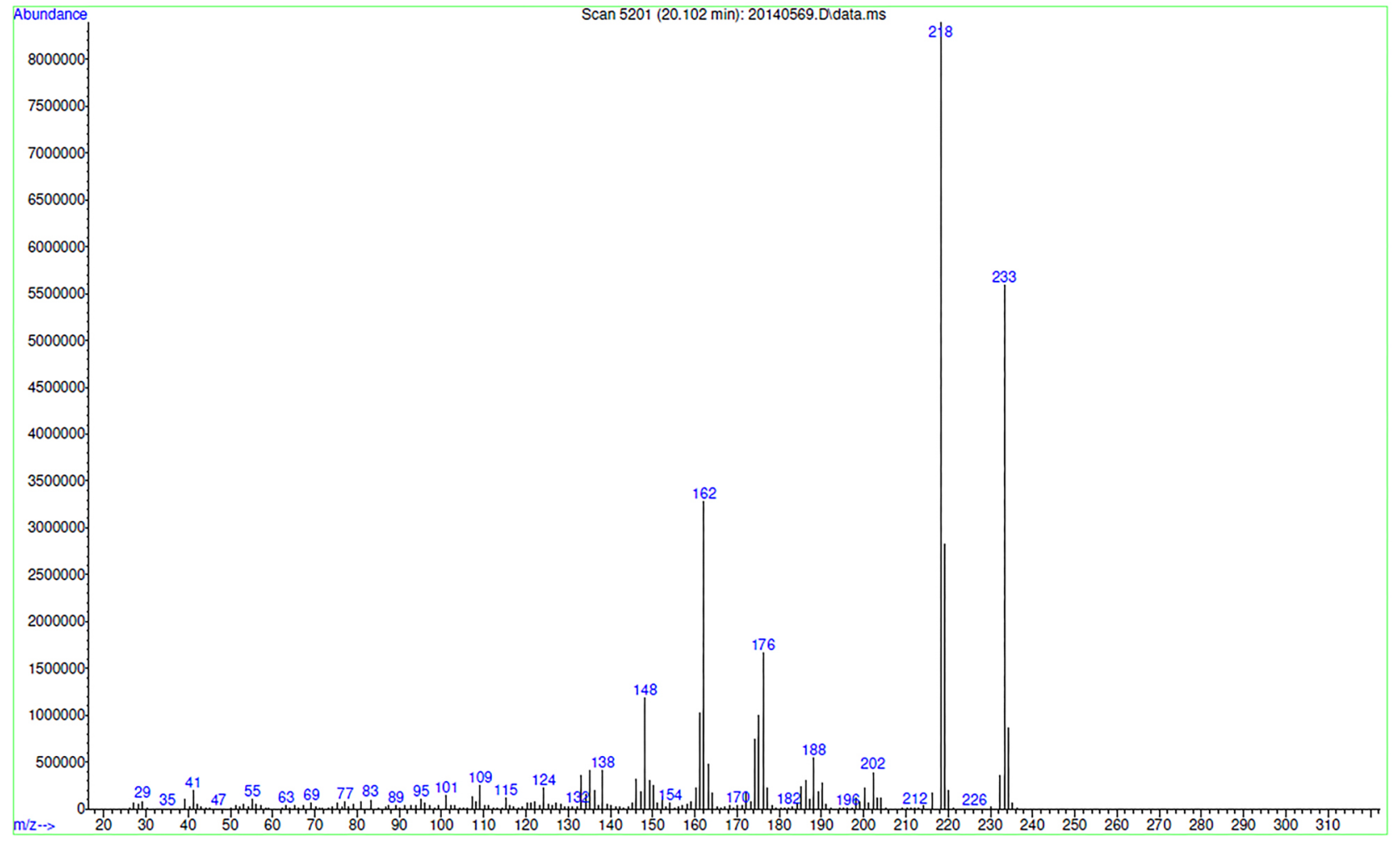

Figure 1. Mass spectra of Schiff base ligand.

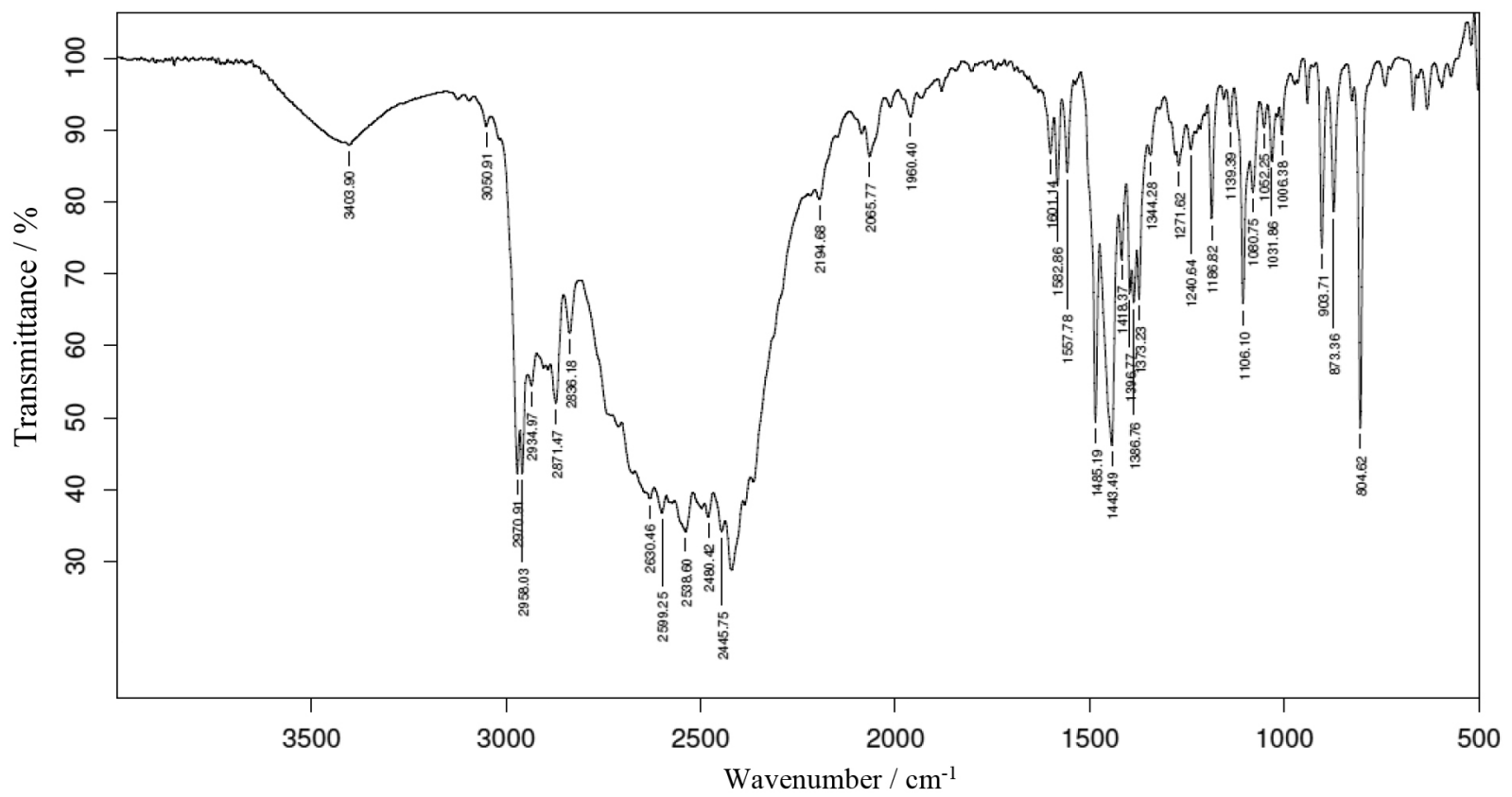

Figure 2. IR spectra of Schiff base ligand.

The $m / z$ of 548.16 (calcd. 548.14) indicate $\left[\mathrm{Cu}(\mathrm{L})_{2} \mathrm{H}_{2} \mathrm{O}\right]$. Further the ion fragmentation of $\mathrm{m} / \mathrm{z} 592.4$ (calcd. $592.1)$ represent $\left[\mathrm{Cu}(\mathrm{L})_{2}\left(\mathrm{NO}_{3}\right)\right]$. MALDI-TOF of $\mathrm{Ni}^{\mathrm{II}}-\mathrm{L}$ complex show the molecular ion peak of $\mathrm{m} / \mathrm{z}, 721.37$ (calcd. 721.35) representing $\left[\mathrm{Ni}(\mathrm{L})_{2}\left(\mathrm{NO}_{3}\right)_{2}\left(\mathrm{H}_{2} \mathrm{O}\right)_{2}\right] 2 \mathrm{H}_{2} \mathrm{O}$.
The $m / z$ of 649.41 (calcd. 649.35) indicate the fragmentation of $\left[\mathrm{Ni}(\mathrm{L})_{2}\left(\mathrm{NO}_{3}\right)_{2}\right]$. Further the molecular ion peak of $\mathrm{m} / \mathrm{z} 587.48$ (calcd. 587.35) indicate the fragmentation of $\left[\mathrm{Ni}(\mathrm{L})_{2}\left(\mathrm{NO}_{3}\right)\right]$. Interestingly MALDI-TOF spectra of cobalt(II) and chromium(III) indicate the formation of 


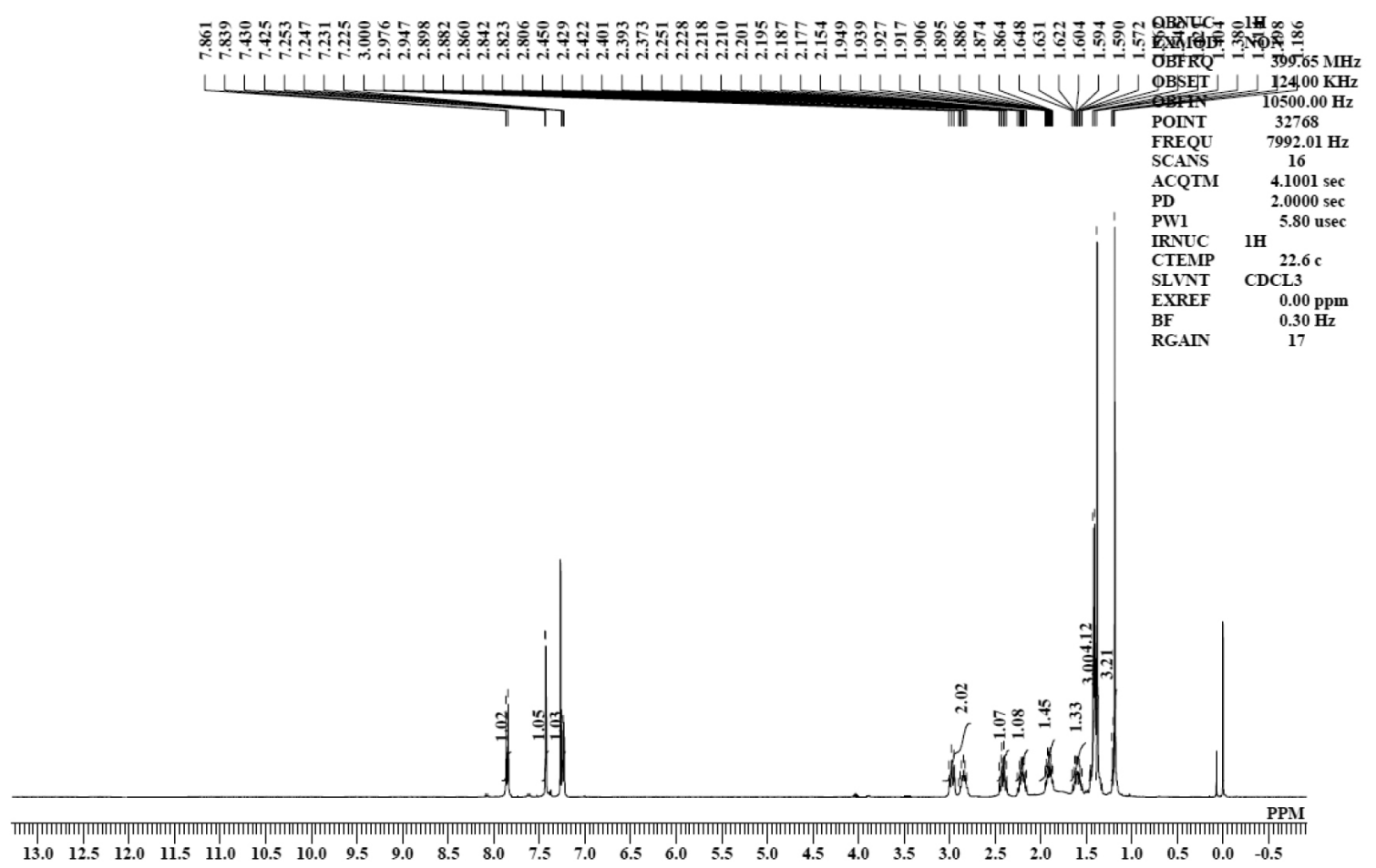

Figure 3. NMR of Schiff base ligand.

binuclear complex. MALDI-TOF spectra of cobalt(II) complex exhibit a molecular ion peak of $m / z, 1264.96$ (calcd. 1264.94) representing $\left[\mathrm{Co}(\mathrm{L})_{2}(\mathrm{Cl})_{2}\left(\mathrm{H}_{2} \mathrm{O}\right)\right]_{2} \cdot 2 \mathrm{H}_{2} \mathrm{O}$ and its fragmentation ion of $\mathrm{m} / \mathrm{z} 650.43$ (calcd. 649.92) represent $\left[\mathrm{Co}(\mathrm{L})_{2}(\mathrm{Cl})_{3}\left(\mathrm{H}_{2} \mathrm{O}\right)\right]$, indicating a binuclear complex and the possible fragmentation of the bridge leading to the $\mathrm{m} / \mathrm{z}$ of 650.43. MALDI-TOF of chromium(III) complex exhibits a molecular ion peak $\mathrm{m} / z, 1303.9$ (calcd. 1303.9), representing $\left[\mathrm{Cr}(\mathrm{L})_{2}(\mathrm{Cl})_{3}\right]_{2} \cdot 3 \mathrm{H}_{2} \mathrm{O}$. The fragmentation at $\mathrm{m} / \mathrm{z} 660.3$ (calcd. 660.4) indicate cleavage of the bridge representing $\left[\mathrm{Cr}(\mathrm{L})_{2}(\mathrm{Cl})_{4}\right]$. The fragmentation at $\mathrm{m} / z 589.7$ (calcd. 589.5) represent $\left[\mathrm{Cr}(\mathrm{L})_{2}(\mathrm{Cl})_{2}\right]$ of the cleavage thereby confirming the binuclear bridging complex (Figures $4 \mathrm{a}$ to $4 \mathrm{~d}$ ).

Thermogram was recorded between 40 to $740{ }^{\circ} \mathrm{C}$ at a heating rate of $10{ }^{\circ} \mathrm{C} \mathrm{min}^{-1}$ under inert atmosphere. The TGA curve of Schiff base ligand exhibit stability up to $180^{\circ} \mathrm{C}$ and degraded completely between 180 to $273^{\circ} \mathrm{C}$ with an estimated loss of $72 \%$ around $222.8^{\circ} \mathrm{C}$ which may be attributed to the good stability of the ligand. The degradation pattern of the metal complexes is tabulated in Table 1.

The weight loses are in line with the proposed structure with the thermogram as depicted in Figures 5a to 5e.

While the IR spectra of the ligand display characteristic band, we obtained the IR of metal complexes which display similarity. The shift in the $(\mathrm{C}=\mathrm{N})$ stretching vibration found in the IR spectra of free ligand at $1601 \mathrm{~cm}^{-1}$ distinctly vary in the complexes. The stretching frequency of the $\mathrm{C}=\mathrm{N}$ bond in free ligand has shifted by 24, 24, 22 and $24 \mathrm{~cm}^{-1}$ for copper(II), nickel(II), cobalt(II) and chromium(III) complexes, respectively. The above shift indicate the co-ordination of azomethine nitrogen with the metal. ${ }^{10,11}$ The complexation leads to reduction in the double bond character of the $\mathrm{C}=\mathrm{N}$ as a result of coordination between nitrogen and central metal atom..$^{12,13}$ The presence of band at $627-635 \mathrm{~cm}^{-1}$ may be assigned specifically to the $\mathrm{O}$ atom of water coordinated to metal..$^{14}$ The IR spectra of metal complexes are depicted in Figures 6a to 6d.

The absorption spectra of the ligand and metal complexes in methanol were recorded over the wavelength range of 200 to $800 \mathrm{~nm}$. The UV spectrum of Schiff base ligand showed sharp absorption maxima and the three main absorption bands at 204, 239 and $286 \mathrm{~nm}$. The first band due to $\pi \rightarrow \pi^{*}$ transitions of the aromatic rings, underwent blue shift in the complexes indicating the metal complex formation. The second band ca. $239 \mathrm{~nm}$ is assigned to the azomethine group of ligand chromophore. The chromium(III) complex underwent blue shift indicating the complex formation. Further weak $\mathrm{d} \rightarrow \mathrm{d}$ transitions were observed owing to the transition metals being Laporte forbidden and hence these spectra were recorded at $100 \mathrm{ppm}^{15}$ (Figures $7 \mathrm{a}$ and $7 \mathrm{~b}$ ).

The molar conductance of all the metal complexes were observed at room temperature in dimethylformamide (DMF) for $10^{-3} \mathrm{M}$ solution and their results $\left(\Omega^{-1} \mathrm{~mol}^{-1} \mathrm{~cm}^{2}\right)$ tabulated (Table 2). 

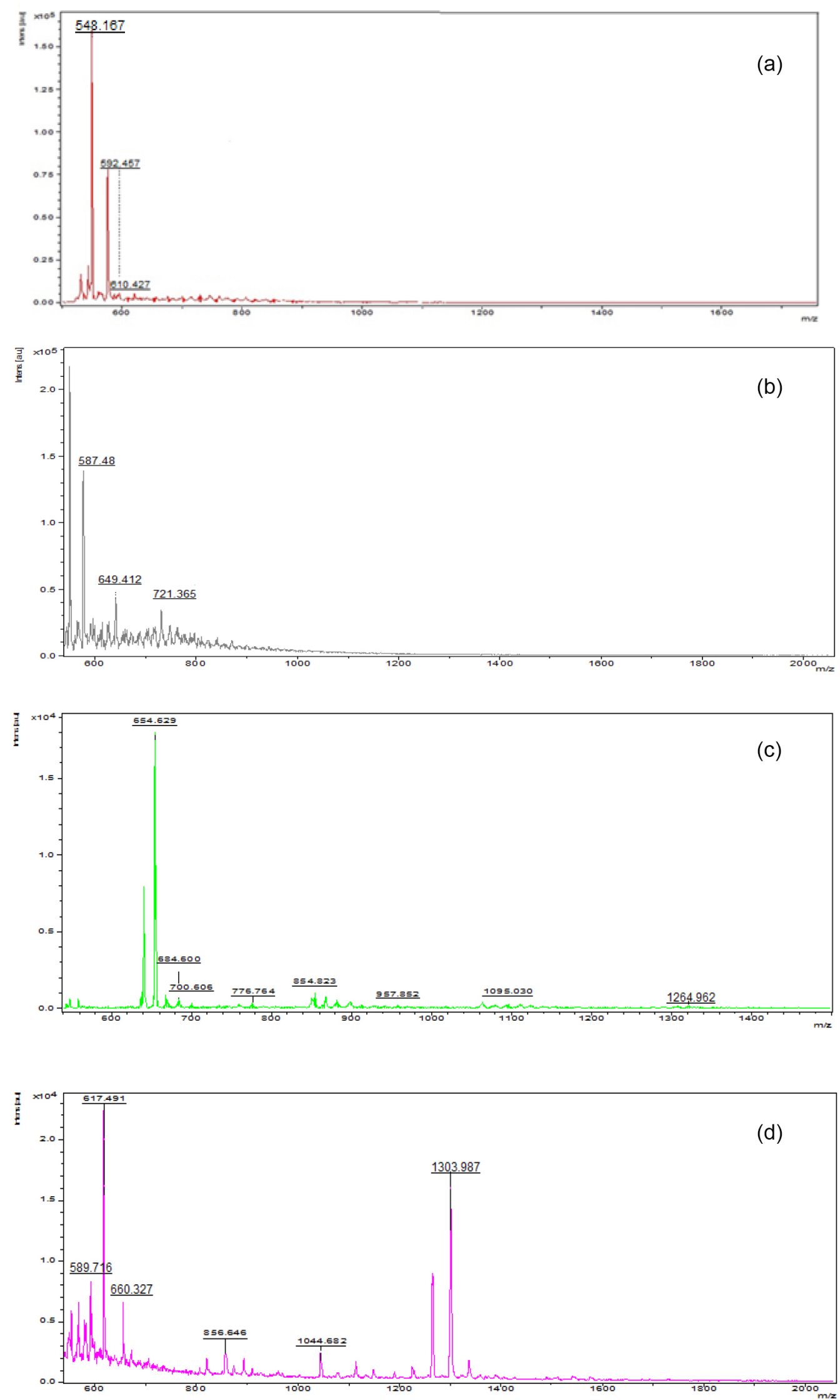

Figure 4. MALDI-TOF of complexes (a) copper(II); (b) nickel(II); (c) cobalt(II); (d) chromium(III). 
Table 1. Thermogram details of the Schiff base ligand and its metal complexes

\begin{tabular}{lccc}
\hline Compound & Temperature range $/{ }^{\circ} \mathrm{C}$ & Weight loss / \% & Attributed to \\
\hline$\left[\mathrm{Cu}(\mathrm{L})_{2}\left(\mathrm{NO}_{3}\right) \mathrm{H}_{2} \mathrm{O}\right](610)$ & 80 to 88 & 2.95 & one molecule in the sphere of co-ordination \\
{$\left[\mathrm{Ni}(\mathrm{L})_{2}\left(\mathrm{NO}_{3}\right)_{2}\left(\mathrm{H}_{2} \mathrm{O}\right)_{2}\right] \cdot 2 \mathrm{H}_{2} \mathrm{O}(721)$} & 95 to 105 & 4.95 & two molecules outside the sphere of co-ordination \\
& 145 to 165 & 5.00 & two molecules in the sphere of co-ordination \\
{$\left[\mathrm{Co}(\mathrm{L})_{2}(\mathrm{Cl})_{2}\left(\mathrm{H}_{2} \mathrm{O}\right)\right]_{2} \cdot 2 \mathrm{H}_{2} \mathrm{O}(1265)$} & 105 to 110 & 2.85 & two molecules outside the sphere of co-ordination \\
& 140 to 150 & 2.87 & two molecules in the sphere of co-ordination \\
{$\left[\mathrm{Cr}(\mathrm{L})_{2}(\mathrm{Cl})_{3}\right]_{2} \cdot 3 \mathrm{H}_{2} \mathrm{O}(1304)$} & 90 to 105 & 4.10 & three molecules outside the sphere of co-ordination \\
\hline
\end{tabular}
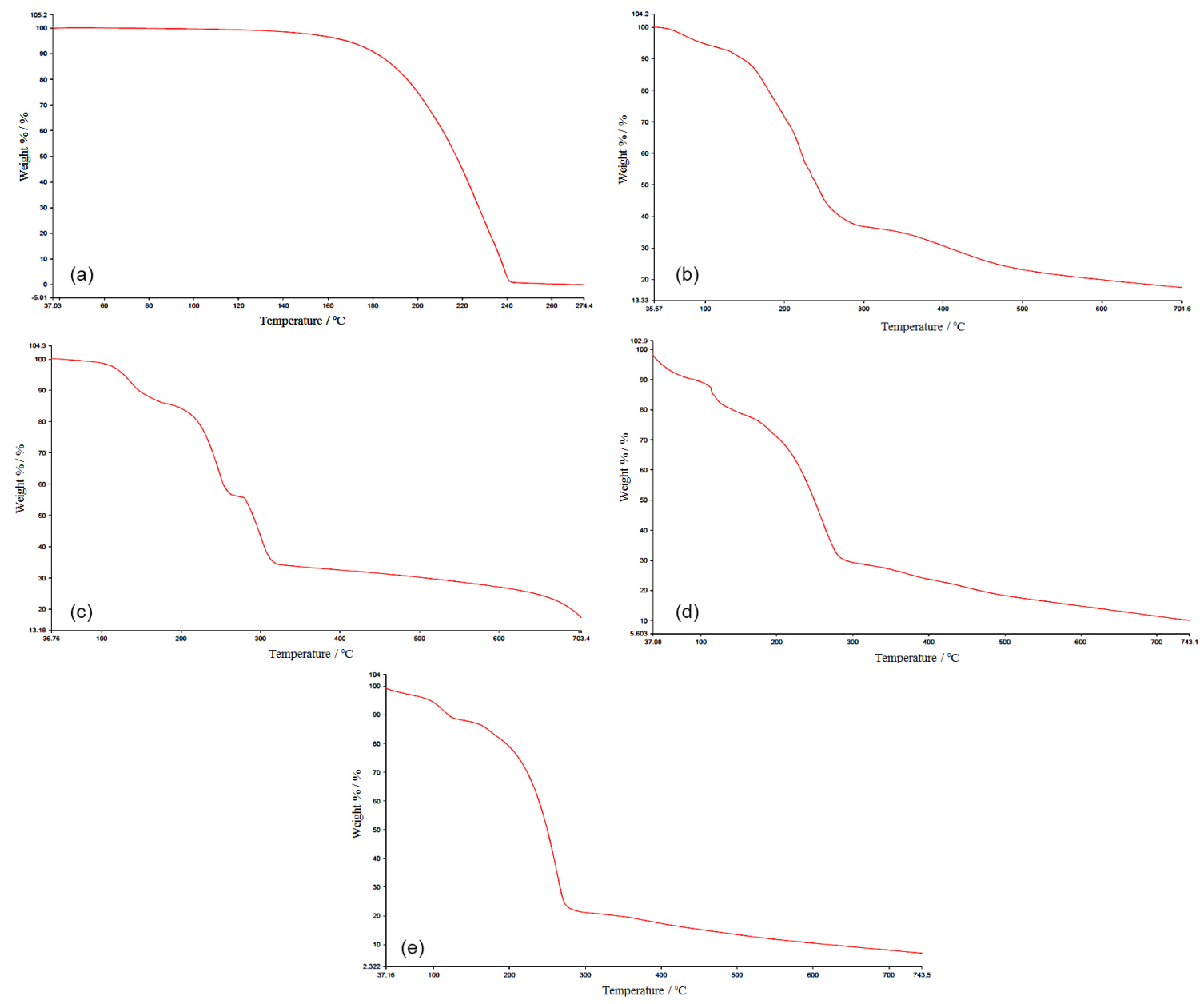

Figure 5. TGA of (a) Schiff base and of metal complexes; (b) copper(II); (c) nickel(II); (d) cobalt(II); (e) chromium(III).

The molar conductivity values of the complexes under investigation were found to be in the range of 18 to $26 \Omega^{-1} \mathrm{~mol}^{-1} \mathrm{~cm}^{2}$, indicating the non-electrolytic nature of the complexes with the chloride or nitrate ions as a part of the coordination spheres. ${ }^{16}$

Fluorescence studied between 200 to $900 \mathrm{~nm}$ for ligand and all the metal complexes demonstrate excellent fluorescence signal with strong and intense peaks. On comparison chromium(III) complex exhibited relatively more fluorescence as compared to rest of the complexes or the ligand (Figure 8).

\section{Theoretical studies}

The ab intio DFT studies were carried out using Gaussian 03 to infer the possible structures from the in silico energetics. The molecules were built in ChemSketch, and minimized by the MMFF94x force fields in MOE before being saved as .pdb files. These files were subsequently studied using Gaussian 03 for their energetics. To optimize the computational cost versus the accuracy, all the molecules were optimized under ONIOM bi-layer model with the high layer consisting of the inner core metals and the complexing 

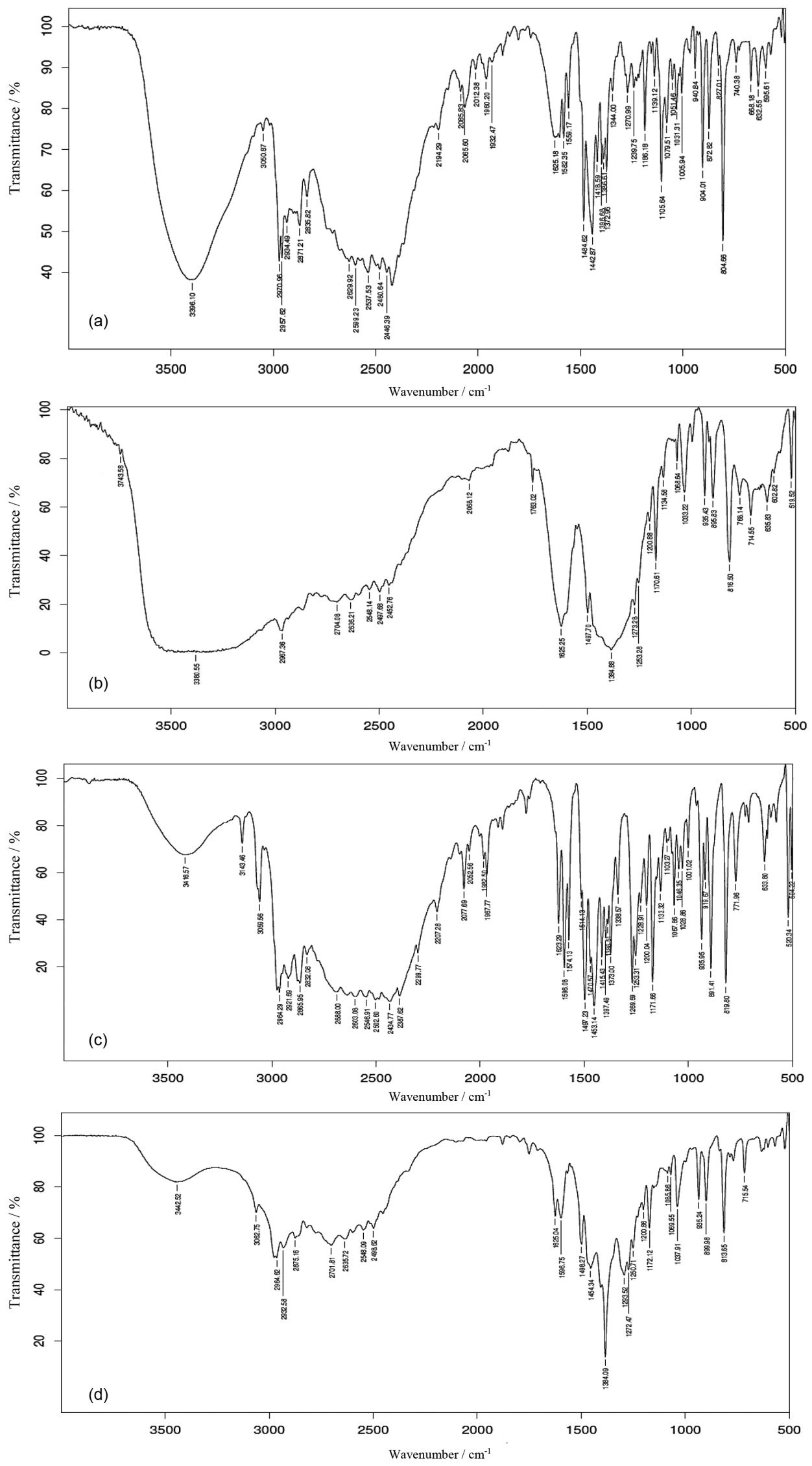

Figure 6. IR spectra of metal complexes (a) copper(II); (b) nickel(II); (c) cobalt(II); (d) chromium(III). 

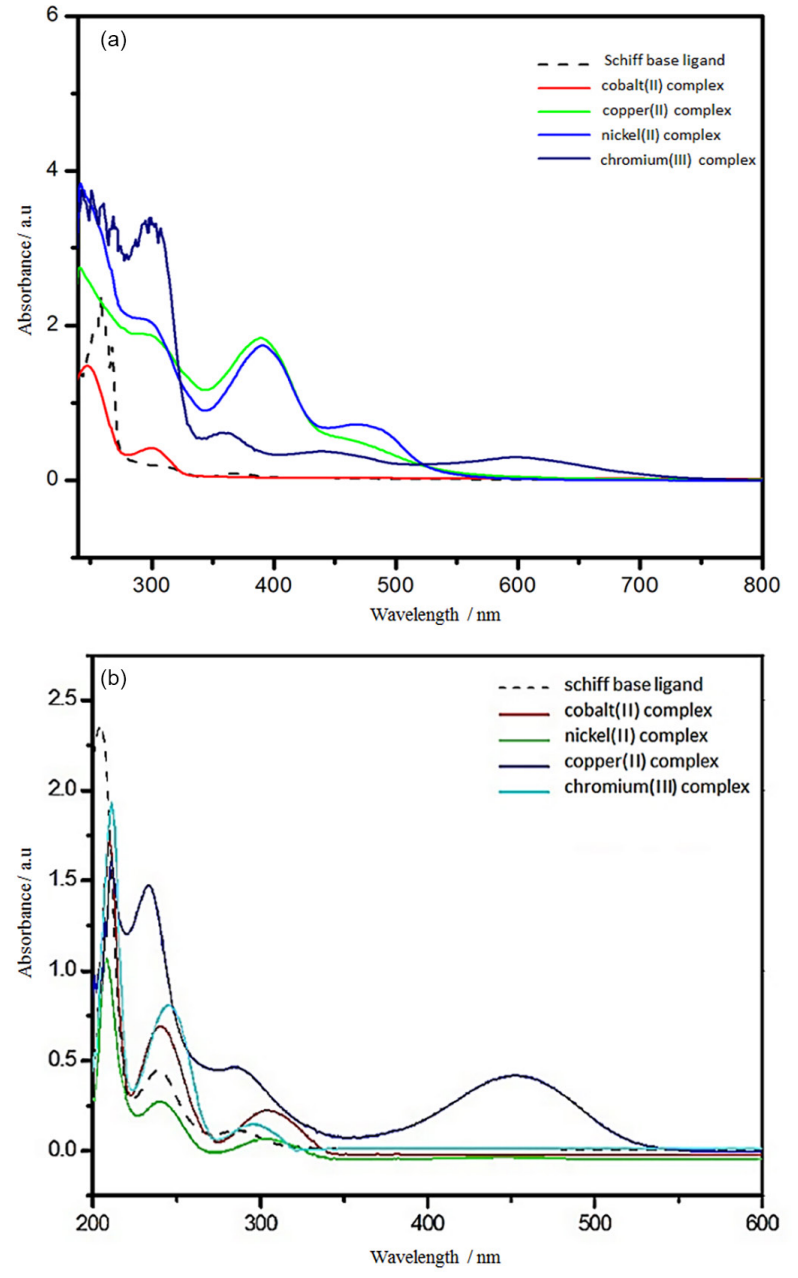

Figure 7. UV-Vis spectra of Schiff base ligand and metal complexes (a) high concentration (100 ppm); (b) low concentration (10 ppm).

Table 2. Molar conductance of the ligand and copper(II), nickel(II), cobalt(II), chromium(III) complexes in DMF

\begin{tabular}{lcc}
\hline Compound & Molecular weight & $\Lambda 10^{-3} \mathrm{M}$ DMF \\
\hline$\left[\mathrm{Cu}(\mathrm{L})_{2}\left(\mathrm{NO}_{3}\right) \mathrm{H}_{2} \mathrm{O}\right]$ & 610 & 24 \\
{$\left[\mathrm{Ni}(\mathrm{L})_{2}\left(\mathrm{NO}_{3}\right)_{2}\left(\mathrm{H}_{2} \mathrm{O}\right)_{2}\right] \cdot 2 \mathrm{H}_{2} \mathrm{O}$} & 721 & 26 \\
{$\left[\mathrm{Co}(\mathrm{L})_{2}(\mathrm{Cl})_{2}\left(\mathrm{H}_{2} \mathrm{O}\right)\right]_{2} \cdot 2 \mathrm{H}_{2} \mathrm{O}$} & 1265 & 18 \\
{$\left[\mathrm{Cr}(\mathrm{L})_{2}(\mathrm{Cl})_{3}\right]_{2} \cdot 3 \mathrm{H}_{2} \mathrm{O}$} & 1304 & 22 \\
\hline
\end{tabular}

DMF: dimethylformamide, $\Lambda$ : molar conductance.

atoms represented by ball, while the rest of the complex was treated as a low layer represented as stick. The high layer was optimized on HF/LANL2DZ while the low layer was optimized on B3PW91/STO-3G (Figures 9a to 9e).

The $\mathrm{Co}-\mathrm{Co}$ distance of $3.309 \AA$ and the $\mathrm{Cr}-\mathrm{Cr}$ distance of $3.298 \AA$ are consistent with the value reported for binuclear cobalt(II) and chromium(III) complexes suggesting the bridging complex. ${ }^{17-19}$ The stabilization energy derived from the DFT studies indicates the stability of the complexes (Table 3 ).

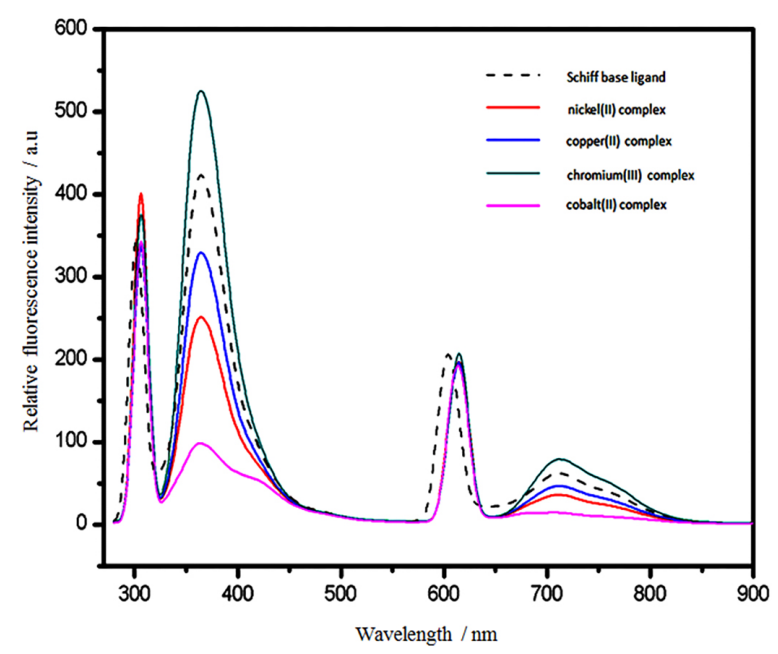

Figure 8. Fluorescence spectra of Schiff base ligand and metal complexes.

Antimicrobial activity

The antibacterial and antifungal activity of Schiff base ligands and the complexes were studied by agar diffusion method. ${ }^{20}$ The sensitivity of a microorganism to antibiotics and other antimicrobial agents was determined by the assay plates, which were incubated at $37^{\circ} \mathrm{C}$ for $24 \mathrm{~h}$ and the diameter of inhibition zone were noted. Gentamycin control wells were also prepared. For measuring the sensitivity to antifungal properties, all the plates were incubated at $27^{\circ} \mathrm{C}$ for $96 \mathrm{~h}$ and the diameter of inhibition zone were noted. The control wells with amphotericin were also prepared.

The studies were conducted against three gram-negative (E. coli (ETEC), S. typhi, P. aeruginosa), three gram-positive (S. aures, B. subtilis, B. megaterium) bacterial strains and six fungi (C. albicans, P. chrysogenum, A. niger, A. flavus, A. fumigatus, $C$. oxysproum) at various concentrations of $25,50,100,200,400,800 \mu \mathrm{g}$. The minimum inhibition concentration (MIC) obtained were compared with that of standard drug gentamcycin for bacteria and amphotericin for fungi, respectively (Tables 4 and 5).

While some of the complexes exhibit moderate activity towards few gram negative and gram positive species, the results of anti-fungal studies are more significant. While the antibacterial activity of the complexes studied is moderate, nickel(II) complex exhibited better activity compared to others. In case of anti-fungal studies, importantly we note that cobalt(II) complex exhibited more activity against Pencillium chrysogenum compared to the reference amphotericin. The chromium(III) complex and ligand exhibit nearly equal activity against this species compared to amphotericin. The typical inhibition of Penicillium chrysogenum by amphotericin, cobalt(II), chromium(III) complexes and ligand [L] are depicted below (Figures 10a to 10e). 
(a)

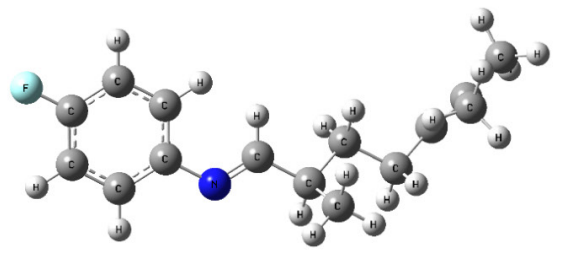

(b)

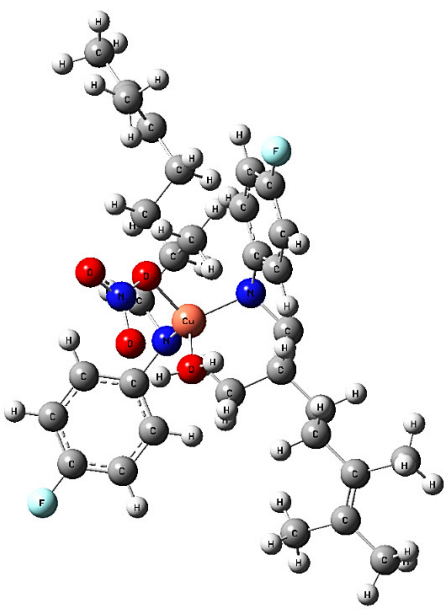

(c)

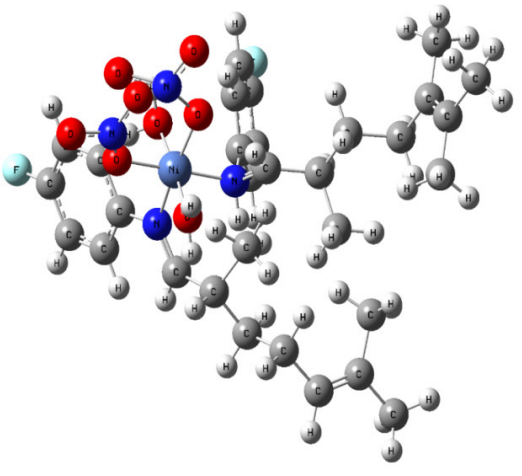

(d)

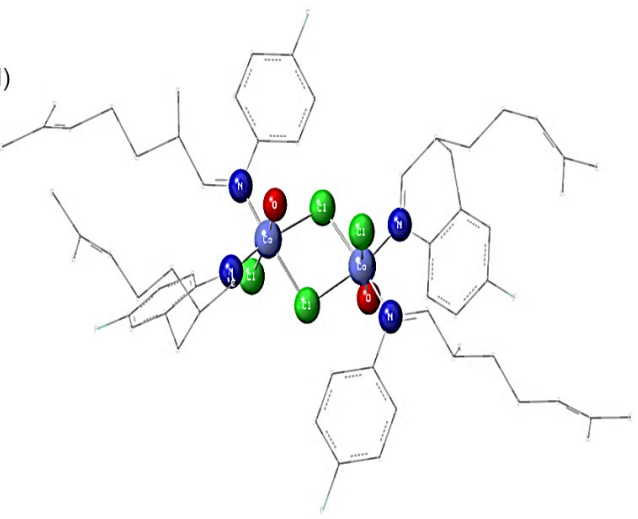

(e)

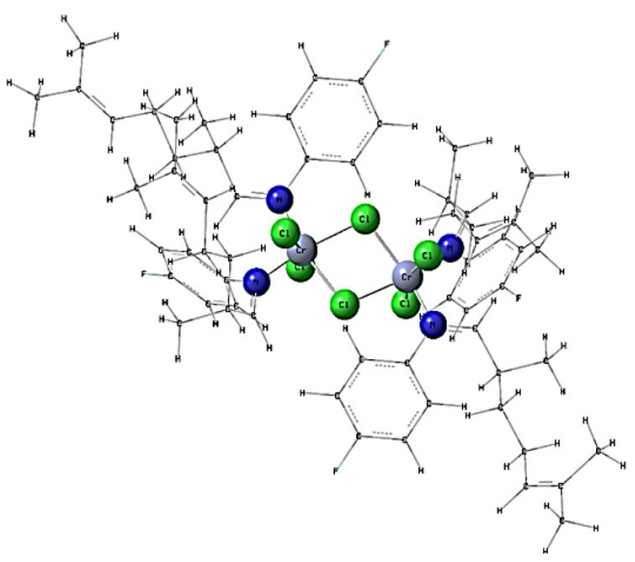

Figure 9. Ball and stick representation of DFT optimized structure of (a) Schiff base ligand and of complexes; (b) copper(II); (c) nickel(II); (d) cobalt(II) and (e) chromium(III).

Table 3. Stabilization energy of the ligand [L] and copper(II), nickel(II), cobalt(II), chromium(III) complexes

\begin{tabular}{lccc}
\hline Compound & $\begin{array}{c}\text { Energy / } \\
\text { a.u. }\end{array}$ & $\begin{array}{c}\text { M-M } \\
\text { distance / } \AA\end{array}$ & $\begin{array}{c}\text { M-Cl bond } \\
\text { length / }\end{array}$ \\
\hline Schiff base ligand & -733.52 & - & - \\
Copper(II) complex & -2046.17 & - & - \\
Nickel(II) complex & -3848.48 & - & - \\
Cobalt(II) complex & -3407.25 & 3.309 & 2.150 \\
Chromium(III) complex & -3169.08 & 3.298 & 2.120 \\
\hline
\end{tabular}

\section{Docking studies}

The PAF protein (PDB ID 2KCN) responsible for the anti-fungal activity in $P$. chrysogenum was obtained from the Protein structure database. The various ligand complexes and the Schiff base ligand were built and minimized in MOE using MMFF94x force-fields. Docking studies were consequently carried out using Hex 8.0 for the metal complexes. The docking returned best poses of best binding unto the PAF protein responsible for the antifungal activity in $P$. chrysogenum. Further, the bacterial activity was evaluated in silico via studying the inhibition of b-ketoacetylacyl carrier protein synthase II (KAS II) of P. Aeruginosa. ${ }^{21}$ The complexes synthesized were docked against the receptor (4JPF) obtained from the protein data bank using Autodock. The binding interactions were noted in MOE and these sites of active residues tabulated (Table 6).

The results of the simulations carried out to evaluate the activity predictions using Hex scores and Autodockvina for the Schiff base ligand and its metal complexes are tabulated (Table 7). 
Table 4. Antibacterial activity of Schiff base ligand and metal complexes copper(II), nickel(II), cobalt(II), chromium(III)

\begin{tabular}{|c|c|c|c|c|c|c|}
\hline \multirow[b]{2}{*}{ Organism } & \multicolumn{6}{|c|}{ MIC (in mm) $/ \mu \mathrm{g}$} \\
\hline & $\begin{array}{l}\text { Schiff base } \\
\text { ligand }\end{array}$ & $\begin{array}{c}\text { Copper(II) } \\
\text { complex }\end{array}$ & $\begin{array}{l}\text { Nickel(II) } \\
\text { complex }\end{array}$ & $\begin{array}{c}\text { Cobalt(II) } \\
\text { complex }\end{array}$ & $\begin{array}{c}\text { Chromium(III) } \\
\text { complex }\end{array}$ & Gentamycin \\
\hline \multicolumn{7}{|l|}{ Gram negative } \\
\hline E. coli (ETEC) & $800(3)$ & $\mathrm{NF}$ & $800(5)$ & $400(5)$ & $400(3)$ & $25(18)$ \\
\hline S. typhi & $800(4)$ & $\mathrm{NF}$ & $800(4)$ & $800(2)$ & $800(5)$ & $25(2)$ \\
\hline$P$. aeruginosa & $400(4)$ & $400(2)$ & $200(2)$ & $400(3)$ & $400(3)$ & $100(1)$ \\
\hline \multicolumn{7}{|l|}{ Gram positive } \\
\hline S. aures & $400(3)$ & $800(2)$ & $800(6)$ & $400(4)$ & $400(5)$ & $25(13)$ \\
\hline B. subtilis & $800(2)$ & $\mathrm{NF}$ & $\mathrm{NF}$ & $200(2)$ & $\mathrm{NF}$ & $25(8)$ \\
\hline B.megaterium & $800(5)$ & NF & $800(4)$ & $800(4)$ & $800(3)$ & $25(7)$ \\
\hline
\end{tabular}

MIC: lowest concentration of drug that inhibits growth of the pathogen; NF: MIC not found in the concentrations screened.

Table 5. Antifungal activity of Schiff base ligand and metal complexes copper(II), nickel(II), cobalt(II), chromium(III)

\begin{tabular}{lcccccc}
\hline \multirow{2}{*}{ Organism } & \multicolumn{9}{c}{ MIC (in mm) / $\mu \mathrm{g}$} \\
\cline { 2 - 7 } & $\begin{array}{c}\text { Schiff base } \\
\text { ligand }\end{array}$ & $\begin{array}{c}\text { Copper(II) } \\
\text { complex }\end{array}$ & $\begin{array}{c}\text { Nickel(II) } \\
\text { complex }\end{array}$ & $\begin{array}{c}\text { Cobalt(II) } \\
\text { complex }\end{array}$ & $\begin{array}{c}\text { Chromium(III) } \\
\text { complex }\end{array}$ & Amphotericin \\
\hline fungi & & & & & & \\
C. albicans & $\mathrm{NF}$ & $\mathrm{NF}$ & $\mathrm{NF}$ & $\mathrm{NF}$ & $400(4)$ & $50(2)$ \\
P. chrysogenum & $800(3)$ & $\mathrm{NF}$ & $\mathrm{NF}$ & $400(3)$ & $800(4)$ & $800(4)$ \\
A. niger & $800(3)$ & $\mathrm{NF}$ & $\mathrm{NF}$ & $800(2)$ & $\mathrm{NF}$ & $100(2)$ \\
A. flavus & $\mathrm{NF}$ & $\mathrm{NF}$ & $\mathrm{NF}$ & $800(4)$ & $\mathrm{NF}$ & $400(7)$ \\
A. fumigatus & $\mathrm{NF}$ & $\mathrm{NF}$ & $400(7)$ & $400(3)$ & $400(2)$ & $200(2)$ \\
C. oxysproum & $\mathrm{NF}$ & $800(3)$ & $\mathrm{NF}$ & $\mathrm{NF}$ & $\mathrm{NF}$ & $50(2)$ \\
\hline
\end{tabular}

MIC: lowest concentration of drug that inhibits growth of the pathogen; NF: MIC not found in the concentrations screened.
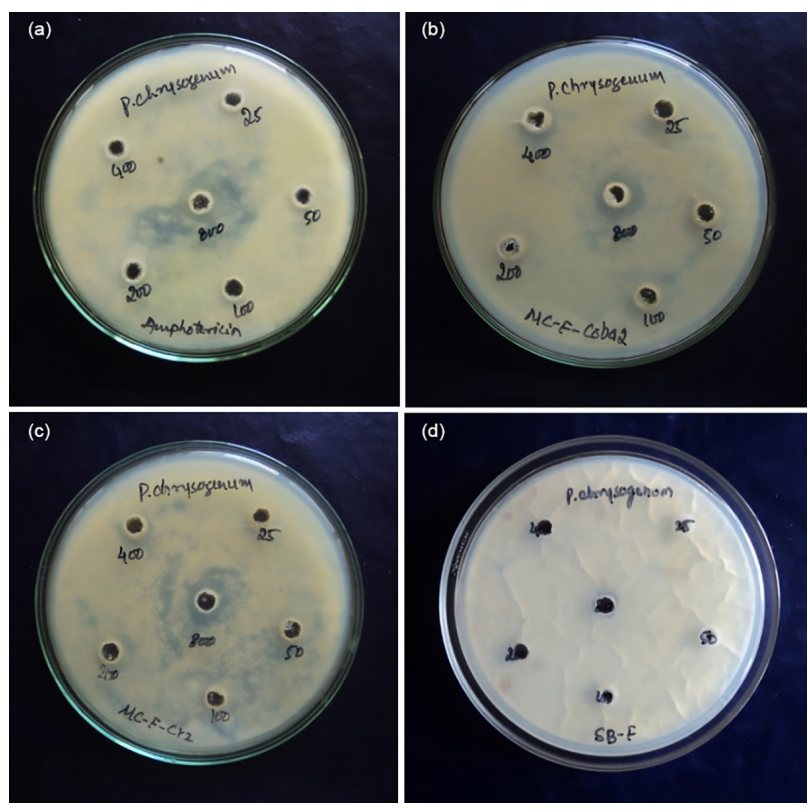

Figure 10. Antifungal activity of (a) amphotericin; metal complexes; (b) cobalt(II); (c) chromium(III); (d) Schiff base ligand.

The binding affinity obtained by auto-docking of ligand is closer to amphotericin which is in line with experimental finding. Also the highest binding affinity as evident from $\mathrm{Ni}$
Table 6. Binding affinity of Schiff base ligand and controls

\begin{tabular}{lccc}
\hline Compound & $\begin{array}{c}\text { Binding affinity } \\
(2 \mathrm{KCN})\end{array}$ & $\begin{array}{c}\text { Binding affinity } \\
\text { (4JPF) }\end{array}$ & Active residue \\
\hline Schiff base ligand & -4.9 & -6.1 & Phe 203 \\
Amphotericin & -5.7 & - & Phe 25, Lys 11 \\
Gentamycin & - & -6.1 & $\begin{array}{c}\text { Asp20, Leu19, } \\
\text { GLn84 }\end{array}$ \\
\hline
\end{tabular}

complex was found to demonstrate the significant bacterial inhibition. The binding interaction of Schiff base ligand with the PAF protein (Figure 11) and the Ni complex (Figure 12) are captured.

\section{Conclusions}

A novel Schiff base ligand was obtained by condensation of 2,6-dimethyl-5-heptenaldehyde with 4-fluoro aniline. The transition metal complexes of copper(II), nickel(II), cobalt(II), and chromium(III) and the Schiff base were synthesized and characterized using MALDI-TOF, GC-MS, ${ }^{1}$ H NMR, FTIR, UV-Vis, TGA and molar conductivity measurements. We obtained novel binuclear complexes 
Table 7. Hex scores of Schiff base ligand, metal complexes

\begin{tabular}{lcccccc}
\hline Activity/affinity & $\begin{array}{c}\text { Schiff base } \\
\text { ligand }\end{array}$ & $\begin{array}{c}\text { Copper(II) } \\
\text { complex }\end{array}$ & $\begin{array}{c}\text { Nickel(II) } \\
\text { complex }\end{array}$ & $\begin{array}{c}\text { Cobalt(II) } \\
\text { complex }\end{array}$ & $\begin{array}{c}\text { Chromium(III) } \\
\text { complex }\end{array}$ & Control drug \\
\hline Antifungal MIC (in mm) / $\mu \mathrm{g}$ & $800(3)$ & $\mathrm{NF}$ & $\mathrm{NF}$ & $400(3)$ & $800(4)$ & $800(4)$ \\
Hex score & -195.4 & -274.6 & -288.2 & -334.0 & -342.4 & -384.3 \\
Antibacterial MIC (in mm) / $\mu \mathrm{g}$ & $400(4)$ & $400(2)$ & $200(2)$ & $400(3)$ & $400(3)$ & $100(1)$ \\
Binding energy & -6.1 & -10.6 & -11.9 & -6.2 & - & -6.1 \\
\hline
\end{tabular}

MIC: lowest concentration of drug that inhibits growth of the pathogen; NF: MIC not found in the concentrations screened.

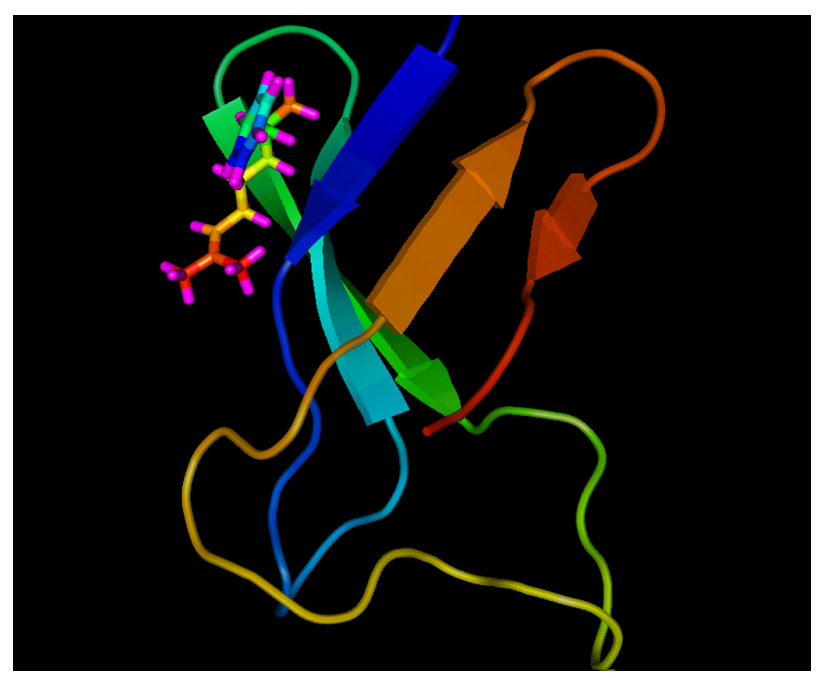

Figure 11. The binding interactions of Schiff base ligand with the PAF protein.

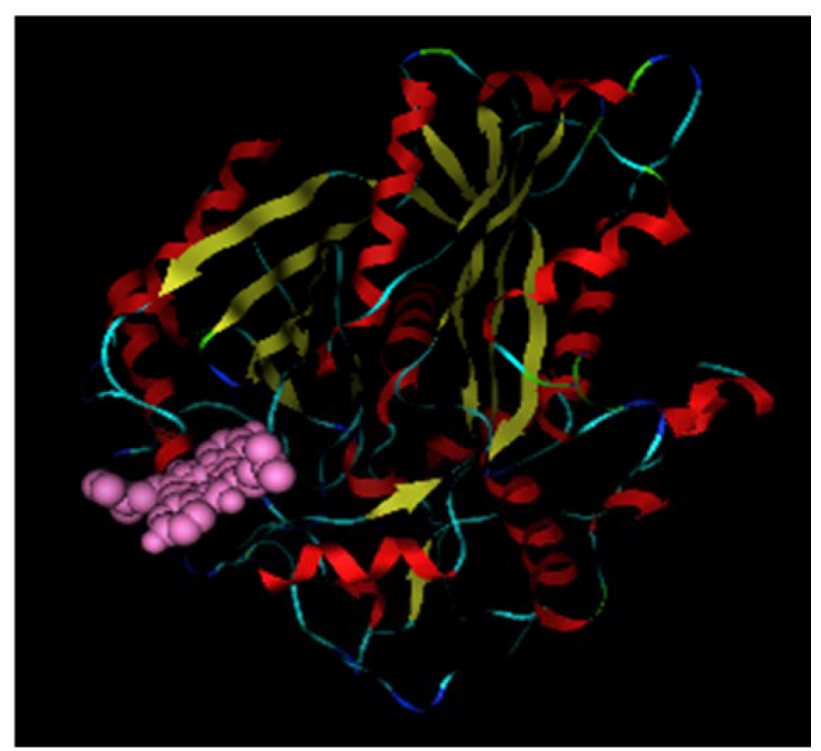

Figure 12. The binding interactions of $\mathrm{Ni}^{\mathrm{II}}$ complex with the KAS II protein.

of cobalt(II) and chromium(III). The theoretical studies lend reliable support to the proposed structures. The Schiff base ligand and its corresponding metal complexes were evaluated for antimicrobial activity against gram-negative bacteria, gram-positive bacteria and fungi. Vital results are noted in the cobalt(II) complex that exhibited better activity against Penicillium chrysogenum compared to reference amphotericin. Further, chromium(III) complex and ligand are noted to demonstrate similar activity against Penicillium chrysogenum compared to its reference amphotericin. Given the findings, cobalt(II)-L complex could evolve as a potential future drug subject to further studies. The computational simulations using auto docking studies for the protein affinity backed these experimental findings.

\section{Acknowledgments}

S. G. acknowledges his colleagues S. Ghajesh, P. Jeevan Kumar and K. Anand Solomon for fruitful discussions.

\section{References}

1. Alcazar-Fuoli, L.; Mellado, E.; Br. J. Haematol. 2014, 166, 471.

2. Parang, K.; Knaus, E. E.; Wiebe, L. I.; Sardari, S.; Daneshtalab, M.; Csizmadia, F.; Arch. Pharm. 1996, 329, 475.

3. Pawar, R. P.; Andurkar, N. M.; Vibhute, Y. B.; J. Indian Chem. Soc. 1999, 76, 76.

4. Singh, H. L.; Varshney, S.; Varshney, A. K.; Appl. Organomet. Chem. 2000, 14, 212.

5. Wang, M.; Wang, L. F.; Li, Y. Z.; Li, Q. X.; Xu, Z. D.; Qu, D. M.; Transition Met. Chem. 2001, 26, 307.

6. Tarasconi, P.; Capacchi, S.; Pelosi, G.; Corina, M.; Albertini, R.; Bonati, A.; Dall'Aglio, P. P.; Lunghi, P.; Pinelli, S.; Bioorg. Med. Chem. 2000, 8, 154.

7. Charo, J.; Lindencrona, J. A.; Carlson, L. M.; Hinkula, J.; Kiessling, R.; J. Virol. 2004, 78, 11321.

8. Nejati, K.; Rezvani, Z.; New J. Chem. 2003, 27, 1665.

9. Silverstein, R. M.; Webster, F. X.; Kiemle, D.; Spectrometric Identification of Organic Compounds, $7^{\text {th }}$ ed.; Wiley: New Jersey, USA, 2005.

10. Nakamoto, K.; Infrared Spectra of Inorganic and Coordination Compounds, vol. 75; John Wiley: New York, USA, 1970.

11. Soliman, A. A.; Linert, W.; Thermochim. Acta 1999, 338, 67.

12. Bagihalli, G. B.; Avaji, P. G.; Patil, S. A.; Badami, P. S.; Eur. J. Med. Chem. 2008, 43, 2639. 
13. Ali, S. A.; Soliman, A. A.; Aboaly, M. M.; Ramadan, R. M.; Coord. Chem. 2002, 55, 1161.

14. Ferraro, J. R.; Low Frequency Vibrations of Inorganic and Coordination Compounds; Springer: New York, USA, 1971, p. 247.

15. Laporte, O.; Meggers, W. F.; J. Opt. Soc. Am. 1925, 11, 459.

16. Alaghaz, A. M. A.; Zayed, M. E.; Alharbi, S. A.; J. Mol. Struct. 2015, 1084, 36.

17. Engelfriet, D. W.; Verschoor, G. C.; den Brinker, W.; Acta Crystallogr. 1980, 36, 1554.
18. Nfor, E.; Keenan, L.; Nenwa, J.; Ndifon, P.; Njong, R.; Dzesse, C.; Offiong, O.; Cryst. Struct. Theory Appl. 2014, 3, 22.

19. Janiak, C.; Silvestre, J.; Theopold, K. H.; Chem. Ber. 1993, 126, 631.

20. Threlfall, E. J.; Fisher I. S. T.; Ward, L.; Tschape, H.; GernerSmidt, P.; Microb. Drug Resist. 1999, 5, 195.

21. Sabbagh, G.; Berakdar, N.; Int. J. Pharm Sci. 2016, 8, 52.

Submitted: June 22, 2016

Published online: August 2, 2016 